\title{
Sensibilidade do algodoeiro ao cloreto de mepiquat em condições salinas $^{1}$
}

\author{
Sensibility of cotton crops to mepiquat chloride under saline conditions
}

\author{
Francisco de Assis de Oliveira ${ }^{2 *}$, José Francismar de Medeiros ${ }^{2}$, Francisco Ronaldo Alves de Oliveira ${ }^{3}$, Mychelle \\ Karla Teixeira de Oliveira ${ }^{4}$ e Alcione Guimarães Freire ${ }^{3}$
}

\begin{abstract}
RESUMO - Este trabalho foi realizado com o objetivo de avaliar o efeito de diferentes níveis de salinidade da água de irrigação e tratamento de sementes com regulador vegetal no desenvolvimento do algodoeiro. O delineamento experimental adotado foi inteiramente ao acaso, arranjados em esquema fatorial 5 x 2 com quatro repetições. Os tratamentos resultaram da combinação de cinco níveis de salinidade da água de irrigação $\left(\mathrm{S}_{1}-0,5 ; \mathrm{S}_{2}-2,0 ; \mathrm{S}_{3}-3,5 ; \mathrm{S}_{4}-5,0\right.$ e $6,5 \mathrm{dS} \mathrm{m}^{-1}$ ) em sementes tratadas e não tratadas com regulador vegetal. As características avaliadas foram: número de folhas, área foliar, altura, massa seca do caule, das folhas e da parte vegetativa, área foliar específica e razão de área foliar. Houve interação entre salinidade e tratamentos de sementes com cloreto de mepiquat apenas para área foliar e razão de área foliar. Todas as demais características foram reduzidas com o aumento da salinidade da água de irrigação, com maiores reduções para área foliar (média de 65,8\%) e massa seca da parte vegetativa (64\%). O tratamento das sementes com cloreto de mepiquat afetou o desenvolvimento das plantas, independente da salinidade.
\end{abstract}

Palavras-chave: Algodão. Plantas-efeito do sal. Plantas-desenvolvimento.

\begin{abstract}
This work was carried out to evaluate the effect of irrigation water at different salinity levels, and of seed treatment with plant growth regulator, on the development of the cotton plant. The experimental design used was completely randomized, arranged in a $5 \times 2$ factorial scheme with four replications. The treatments resulted from the combinations of five levels of salinity of the irrigation water $\left(\mathrm{S}_{1}-0.5, \mathrm{~S}_{2}-2.0, \mathrm{~S}_{3}-3.5, \mathrm{~S}_{4}-5.0\right.$ and $\left.6.5 \mathrm{dS} \mathrm{m} \mathrm{m}^{-1}\right)$ on seeds, both treated and not treated with growth regulator. The evaluated characteristics were: number of leaves, leaf area, height, dry mass of stems, leaves and vegetative parts, specific leaf area and leaf area ratio. There was an interaction between salinity and seed treatments with mepiquat chloride, but only for leaf area and leaf area ratio. All other characteristics decreased with the increasing salinity of the irrigation water, with greater reductions in leaf area (mean of $65.8 \%$ ) and dry mass of vegetative parts $(64 \%)$. Seed treatment with mepiquat chloride affected plant development, independent of salinity.
\end{abstract}

Key words: Cotton. Plants-salt effect on. Plants-development.

\footnotetext{
* Autor para correspondência

'Recebido para publicação em 04/03/2011; aprovado em 30/08/2011

Pesquisa desenvolvida através de convênio FINEP/FAPERN/PRODECOT e UFERSA

${ }^{2}$ Departamento de Ciências Ambientais e Tecnológicas, UFERSA, Mossoró-RN, Brasil, 59.625-900, thikaoamigao@ufersa.edu.br; jfrancismar. rn@uol.com.br

${ }^{3}$ Pós-Graduação em Agronomia: Solos e Nutrição de Plantas, Departamento de Ciências do Solo/ UFC, Campus do Pici, Bloco 807, Fortaleza-CE, Brasil, 60.455-760, ronaldoindep@yahoo.com.br; alcionegf@ hotmail.com

${ }^{4}$ Pós-Graduação em Fitotecnia/UFERSA, Mossoró-RN, Brasil, 59.625-900, mkto10@ hotmail.com
} 


\section{INTRODUÇÃO}

O algodoeiro herbáceo (Gossypium hirsutum L.r. latifolium Hutch.) é uma das principais culturas exploradas no Brasil, cultivada em mais de quinze Estados. Ao decorrer de 10 anos, entre 1998 e 2008, o Brasil passou de importador para exportador de algodão, ocupando a quinta colocação dentre os países que mais produzem a cultura no mundo, respondendo por 5,7\% da produção (COSTA et al., 2008).

A cotonicultura tem se destacado como uma das atividades agrícolas de maior importância para o agronegócio brasileiro, tal fato deve-se ao crescente desenvolvimento de pesquisas objetivando o aumento da eficiência produtiva, com destaque para estudos envolvendo a fisiologia das plantas.

A irrigação é uma das tecnologias de maior influência no desenvolvimento e produção das culturas, minimizando os efeitos nocivos das secas periódicas e da irregularidade das chuvas, condições edafoclimáticas típicas de regiões áridas e semiáridas. Silva e Rao (2005) afirmam que a retomada da produção no Nordeste do Brasil está condicionada à aplicação de novas tecnologias, principalmente às relacionadas ao uso eficiente da água que provocará benefícios ambientais e redução nos custos de produção.

Esses estudos enfocam respostas das plantas às condições adversas do ambiente de cultivo, principalmente quando o cultivo é realizado em solo salinizado ou a irrigação é realizada utilizando águas com elevada concentrações de sais dissolvidos. Apesar do algodoeiro ser considerado uma cultura tolerante à salinidade (TAIZ; ZEIGER, 2009), estudos têm observado efeitos deletérios do estresse salino sobre o desempenho produtivo, sendo essa resposta variada em função do genótipo e do manejo adotado (JÁCOME et al., 2003).

Os efeitos da salinidade da água de irrigação sobre as plantas se refletem em alterações no potencial osmótico, na toxicidade dos íons e no desequilíbrio nutricional das plantas (FERREIRA et al., 2007). A inibição do crescimento das plantas sob salinidade ocorre por duas razões, a primeira se deve ao efeito osmótico provocado pela salinidade, que reduz a absorção de água e a segunda, se dá devido ao efeito específico dos íons ou ao excesso, que entram no fluxo de transpiração e, eventualmente, causam injúrias nas folhas, reduzindo o crescimento ou influenciando negativamente na absorção de elementos essenciais (MUNNS, 2002, 2005).

Atualmentetem-seintensificadoousodereguladores vegetais na cultura do algodoeiro, principalmente, do cloreto de mepiquat, um inibidor da síntese de giberelinas, para manejar o crescimento da altura, uniformizar o desenvolvimento e a maturação do algodoeiro. A eficiência do seu uso depende, além de outros fatores, das condições edafoclimáticas em determinada região.

Estudos têm demonstrado que o efeito do cloreto de mepiquat sobre o desenvolvimento das plantas pode ser diferente em função de diversos fatores, como a variabilidade genética (BOGIANI; ROSOLEM, 2009), umidade do solo (CORDÃO SOBRINHO et al., 2007), forma de aplicação do regulador de vegetal (NAGASHIMA et al., 2007, 2010) e adubação nitrogenada (TEIXEIRA et al., 2008).

Apesar da importância no uso desta tecnologia para o desenvolvimento da cotonicultura brasileira, ainda são escassos estudos sobre a eficiência do cloreto de mepiquat sobre diferentes condições de cultivo. Na literatura brasileira, praticamente não existem estudos sobre o efeito do regulador vegetal sobre o algodoeiro irrigado com água salina; desta forma, este trabalho foi desenvolvido com plantas de algodão provenientes de sementes embebidas em cloreto de mepiquat e irrigadas com água salina.

\section{MATERIAL E MÉTODOS}

$\mathrm{O}$ experimento foi conduzido no período de fevereiro a abril de 2009 em casa de vegetação, do Departamento de Ciências Ambientais e Tecnológicas (DCAT) da Universidade Federal Rural do Semi-Ârido (UFERSA), localizado no município de Mossoró, RN, conforme as coordenadas geográficas de $5^{\circ} 11^{\prime} 31^{\prime \prime}$ de latitude Sul e 37 $20^{\prime} 40^{\prime \prime}$ de longitude Oeste de Greenwich e com altitude média de $18 \mathrm{~m}$.

A estrutura da casa de vegetação é de aço galvanizado, sendo as partes laterais e frontais confeccionadas com tela negra (sombrite) com 50\% de sombreamento. A cobertura era em arco tipo túnel, medindo 7,0 m de largura e 18,0 m de comprimento, com manta de polietileno de baixa densidade, transparente, com $0,15 \mathrm{~mm}$ de espessura.

$\mathrm{O}$ delineamento experimental utilizado foi inteiramente ao acaso, com os tratamentos distribuídos em esquema fatorial $5 \times 2$, com quatro repetições, sendo a unidade experimental representada por um vaso com capacidade para $12 \mathrm{dm}^{3}$, contendo uma planta. Os tratamentos resultaram da combinação de cinco níveis de condutividade elétrica da água de irrigação $\left(S_{1}-0,5\right.$; $\left.\mathrm{S}_{2}-2,0 ; \mathrm{S}_{3}-3,5, \mathrm{~S}_{4}-5,0 \mathrm{e} \mathrm{S}_{5}-6,5 \mathrm{dS} \mathrm{m}^{-1}\right)$ com duas condições de sementes $\left(S_{1}\right.$ - Sementes tratadas com cloreto de mepiquat e $S_{2}$ - Sementes não tratadas), com.

As sementes foram tratadas através de embebição em solução de cloreto de mepiquat na concentração de $7,5 \%$ (v/v) por um período de 12 horas, em seguida, estas foram secas à sombra e conservadas em sacos de papel até a semeadura (NAGASHIMA et al., 2007), que foi realizada cinco dias após o tratamento. 
Foram semeadas cinco sementes da cultivar NuOpal em cada vaso, e cinco dias após a emergência das plântulas realizou-se o desbaste deixando em cada vaso a plântula mais vigorosa. Utilizou-se esta cultivar devido à mesma ser responsiva à aplicação deste regulador de vegetal, conforme observado por Bogiani e Rosolem (2009), bem como por apresentar tolerância à salinidade (FURTADO et al., 2007).

Os diferentes níveis de salinidade foram obtidos pela dissolução de cloreto de sódio $(\mathrm{NaCl})$ em água proveniente do sistema de abastecimento do campus da UFERSA $\left(\mathrm{S}_{1}\right)$, ajustando-se com condutivímetro de bancada, com correção automática de temperatura. A água utilizada para representar o nível de salinidade de $0,5 \mathrm{dS} \mathrm{m}^{-1}$ e na obtenção das demais salinidades apresentou as seguintes características químicas: $\mathrm{pH}=8,30$; $\mathrm{CE}=0,50 \mathrm{dS} \mathrm{m}{ }^{-1} ; \mathrm{Ca}^{2+}=3,10 ; \mathrm{Mg}^{2+}=1,10 ; \mathrm{K}^{+}=0,30 ;$ $\mathrm{Na}^{+}=2,30 ; \mathrm{Cl}^{-}=1,80 ; \mathrm{HCO}_{3}^{-}=3,00 ; \mathrm{CO}_{3}^{2-}=0,20\left(\mathrm{mmol}_{\mathrm{c}} \mathrm{L}^{-1}\right)$.

Foi utilizado material de solo classificado como Latossolo Vermelho Amarelo Argissólico franco arenoso, coletado na camada de 0-30 m de profundidade, em área não cultivada localizada no Campus da UFERSA. O material coletado foi seco ao ar e, posteriormente, peneirado em malha de 2,0 $\mathrm{mm}$. Antes do acomodamento do solo nos vasos foi retirada uma subamostra para ser submetida às análises físico-químicas (EMBRAPA, 1997), cujos resultados são apresentados na Tabela 1.

O solo foi peneirado e acondicionado em vasos, deixando-se cerca de $2 \mathrm{~cm}$ entre a superfície do solo e a borda superior do vaso para facilitar a irrigação, evitando possível transbordamento da água durante as irrigações, que foram realizadas manualmente, utilizando proveta graduada $(500 \mathrm{~mL})$. O material de solo foi acondicionado em cada vaso de forma que, após o término do enchimento, fosse obtida densidade semelhante àquela obtida na análise física.

Foi realizada adubação de fundação com N, P e K, aplicando-se 100; $200 \mathrm{e} 100 \mathrm{mg} \mathrm{dm}^{-3}$ de solo, respectivamente, utilizando os seguintes fertilizantes: uréia para fornecimento de $\mathrm{N}$, fosfatomonoamônico para o fornecimento de $\mathrm{P}$ e de $\mathrm{N}$ e cloreto de potássio para K. Os fertilizantes foram diluídos em água e aplicando-se em cada vaso volume suficiente para elevar o teor de água do solo até a umidade correspondente à máxima capacidade de retenção de água do material do solo (capacidade de vaso).

No período entre a semeadura e o desbaste a irrigação foi realizada utilizando-se água proveniente do sistema de abastecimento do campus da UFERSA $\left(\mathrm{S}_{1}\right)$. No dia seguinte, após o desbaste, a irrigação foi realizada utilizando água com diferentes níveis salinos, de acordo com os tratamentos utilizados.

O suprimento hídrico das plantas foi realizado com frequência de uma irrigação diária até os 30 dias após a semeadura (DAS), enquanto que do $31^{\circ} \mathrm{DAS}$ até a colheita foi adotada a frequência de duas aplicações por dia, uma pela manhã e outra à tarde, de acordo com a necessidade da cultura. Em cada irrigação foi aplicado volume de água suficiente para elevar a umidade do solo próximo da máxima capacidade de retenção de água no solo, sendo o volume de água aplicado determinado por meio de pesagens diárias.

Aos 110 dias após a semeadura as plantas foram coletadas, cortando-as rente ao solo, ensacando-as e transportado-as para o Laboratório de Irrigação e Salinidade da UFERSA, para serem analisadas quanto as seguintes variáveis: ao número de folhas (NF), área foliar (AF), altura (ALT), massa da matéria seca das folhas (MSF), do caule (MSC) e da parte vegetativa (MSPV). A partir dos valores de AF, MSF e MSPV foram determinadas a área foliar específica (AFE) e a razão de área foliar (RAF). A AFE foi obtida pela relação entre a $\mathrm{AF}$ e a $\mathrm{MSF}$ ( $\left.\mathrm{cm}^{2} \mathrm{~g}^{-1} \mathrm{MSF}\right)$, enquanto a RAF foi determinada pela relação entre AF e MSPV $\left(\mathrm{cm}^{2} \mathrm{~g}^{-1} \mathrm{MSPV}\right)$.

A área foliar foi determinada através de um integrador de área, marca LI-COR, modelo LI-3100. Em seguida, as amostras foram acondicionadas em sacos de

Tabela 1 - Características físicas e químicas dos solos utilizados no experimento

\begin{tabular}{|c|c|c|c|c|c|c|c|c|}
\hline \multicolumn{9}{|c|}{ Características químicas } \\
\hline $\mathrm{pH}$ & M.O. & $\mathrm{P}$ & $\mathrm{K}^{+}$ & $\mathrm{Na}^{+}$ & $\mathrm{Ca}^{+2}$ & $\mathrm{Mg}^{+2}$ & $\mathrm{Al}^{+3}$ & $\mathrm{H}^{+}$ \\
\hline & $(\%)$ & $\left(\mathrm{mg} \mathrm{dm}^{-3}\right)$ & \multicolumn{6}{|c|}{ 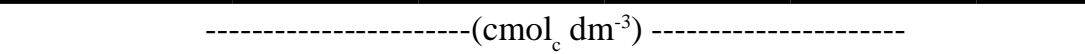 } \\
\hline 5,3 & 1,05 & 2,20 & 0,14 & 0,13 & 0,40 & 0,60 & 0,25 & 3,05 \\
\hline \multicolumn{9}{|c|}{ Características físicas } \\
\hline \multicolumn{3}{|c|}{ Fração granulométrica $\left(\mathrm{g} \mathrm{kg}^{-1}\right)$} & Classe textural & Umidade & & Densidad & $\left.\mathrm{Im}^{3}\right)$ & \\
\hline Areia & Silte & Argila & & $\mathrm{CC}$ & PMP & Ds & \multirow{2}{*}{\multicolumn{2}{|c|}{ Dp 2,68 }} \\
\hline 707,2 & 172,2 & 120,6 & FA & 0,15 & 0,06 & 1,53 & & \\
\hline
\end{tabular}

FA - Franco Arenoso; CC - Capacidade de Campo para $\psi_{\mathrm{m}}=-10 \mathrm{KPa}$; PMP - Ponto de Murcha Permanente para $\psi_{\mathrm{m}}=-1500 \mathrm{KPa}$; Ds - Densidade do solo ou aparente; DP - Densidade de Partículas 
papel e colocadas para secar em estufa com circulação forçada de ar, à temperatura de $65^{\circ} \mathrm{C}$ até atingir pesos constantes, determinados em balança de precisão $(0,01 \mathrm{~g})$.

Os dados obtidos foram submetidos à análise de variância e as médias resultantes do tratamento de semente comparadas entre si aplicando-se o teste Tukey ao nível de 5\% de probabilidade. Os resultados do efeito da salinidade foram submetidos à análise de regressão.

\section{RESULTADOS E DISCUSSÃO}

Foi observado efeito significativo da interação salinidade e tipos de sementes (tratadas - S1, não tratadas - S2) para área foliar (AF), ao nível de significância de $1 \%$ de probabilidade, sendo observado efeito isolado dos fatores para as demais características avaliadas e interação significativa para razão de área foliar (RAF) a 5\%. A salinidade da água de irrigação afetou significativamente o número de folhas (NF), área foliar (AF), altura (ALT), massa seca do caule (MSC) e da parte vegetativa (MSPV) $(\mathrm{p}<0,01)$, bem como a massa seca das folhas (MSF) $(\mathrm{p}<0,05)$. Com relação ao tratamento das sementes, verificou-se efeito significativo para AF, ALT, MSC e MSPV ( $p<0,01$ ). Não houve efeito dos tratamentos sobre a área foliar específica (TAB. 2).

\section{Efeito da condutividade elétrica da água de irrigação}

O número de folhas por planta foi reduzido pelo aumento da salinidade, ajustando-se à equação linear decrescente, sendo reduzido em cerca de 4,23 folhas por planta em resposta ao incremento unitário da condutividade da água de irrigação, resultando em perda total nas plantas irrigadas com a água de maior salinidade $\left(6,5 \mathrm{ds} \mathrm{m}^{-1}\right) \mathrm{em}$ cerca de $52,5 \%$, em relação às plantas irrigadas com água sem adição de sais $\left(0,5 \mathrm{dS} \mathrm{m}^{-1}\right)$ (FIG. 1A). Esses resultados corroboram os obtidos por Siqueira et al. (2005), que estudando o crescimento do algodoeiro de fibra colorida em condições salinas, verificaram redução de $40,7 \%$ no número de folhas para plantas irrigadas com água de condutividade elétrica de $6,5 \mathrm{dS} \mathrm{m}^{-1}$.

A redução no número de folhas pode ser justificada considerando que uma das alterações fisiológicas em relação ao estresse hídrico, provocado pela redução no potencial osmótico, é a maior produção endógena de hormônios vegetais, como o ácido abscísico e o etileno, e na presença desses compostos há maior senescência e abscisão foliar, comportamento semelhante ao observado por Carlesso et al. (2007) e Baldo et al. (2009).

A área foliar foi reduzida pela salinidade da água de irrigação tanto para sementes tratadas como para não tratadas; no entanto, verificou-se que a intensidade do efeito da salinidade variou de acordo com o tratamento da semente. Para ambos os casos foi ajustada equação de regressão linear decrescente, no entanto, o efeito da salinidade foi mais severo nas plantas oriundas de sementes tratadas, sendo observada redução de $209,54 \mathrm{~cm}^{2}$ planta $^{-1}$ para cada incremento de uma unidade na condutividade elétrica da água, com redução total de $60,8 \%$ na maior

Tabela 2 - Resumo da análise de variância (Valores de 'F') e análise de regressão para número de folhas (NF), área foliar (AF), altura (ALT), massa seca de caule (MSC), das folhas (MSF) e da parte vegetativa (MSPV), área foliar específica (AFE) e razão de área foliar (RAF) do algodoeiro em função da salinidade da água de irrigação e do tratamento de sementes com cloreto de mepiquat

\begin{tabular}{|c|c|c|c|c|c|c|c|c|c|}
\hline \multirow{2}{*}{ Fontes de variação } & \multirow{2}{*}{ GL } & \multicolumn{8}{|c|}{ Valores de 'F' } \\
\hline & & NF & $\mathrm{AF}$ & ALT & MSC & MSF & MSPV & AFE & RAF \\
\hline Sementes $(\mathrm{S})$ & 1 & $0,68^{\text {ns }}$ & $7,19 * *$ & $171,67 * *$ & $35,23 * *$ & $7,39 * *$ & $40,55 * *$ & $1,71^{\mathrm{ns}}$ & $2,15^{\mathrm{ns}}$ \\
\hline Salinidade (Sal) & 4 & $42,35 * *$ & $39,97 * *$ & $27,15^{* *}$ & $20,99 * *$ & $43,84 * *$ & $72,50 * *$ & $2,06^{\mathrm{ns}}$ & $0,69^{\mathrm{ns}}$ \\
\hline S x Sal & 4 & $1,55^{\mathrm{ns}}$ & $4,07 * *$ & $0,63^{\mathrm{ns}}$ & $0,59^{\mathrm{ns}}$ & $1,44^{\mathrm{ns}}$ & $1,80^{\mathrm{ns}}$ & $1,95^{\mathrm{ns}}$ & $3,08^{*}$ \\
\hline $\mathrm{CV}(\%)$ & & 12,37 & 13,74 & 8,40 & 10,68 & 11,66 & 9,53 & 11,47 & 11,34 \\
\hline \multicolumn{10}{|c|}{ Equações de regressão (salinidade) } \\
\hline \multicolumn{10}{|c|}{ Sementes tratadas com cloreto de mepiquat } \\
\hline Linear & 1 & $63,84 * *$ & $117,22 * *$ & $47,13 * *$ & $39,91 * *$ & $107,3 * *$ & $149,1 * *$ & $4,05^{\text {ns }}$ & $6,53 *$ \\
\hline Quadrática & 1 & $0,77^{\mathrm{ns}}$ & $11,42 * *$ & $5,35^{*}$ & $0,58^{\mathrm{ns}}$ & $0,19^{\text {ns }}$ & $3,71^{\mathrm{ns}}$ & $8,75^{* *}$ & $3,85^{\text {ns }}$ \\
\hline \multicolumn{10}{|c|}{ Sementes sem tratamento } \\
\hline Linear & 1 & $102,54 * *$ & $46,17^{\mathrm{ns}}$ & $57,51 * *$ & $45,57 * *$ & $64,43 * *$ & $135,4 * *$ & $0,02^{\text {ns }}$ & $1,08^{\text {ns }}$ \\
\hline Quadrática & 1 & $1,32^{\text {ns }}$ & $0,31^{\mathrm{ns}}$ & $0,17^{\mathrm{ns}}$ & $0,91^{\mathrm{ns}}$ & $0,43^{\text {ns }}$ & $0,08^{\mathrm{ns}}$ & $0,02^{\mathrm{ns}}$ & $0,26^{\mathrm{ns}}$ \\
\hline
\end{tabular}

* e ** Significativo a 0,05 e a 0,01 , respectivamente; ns - não significativo pelo teste $\mathrm{F}$ 


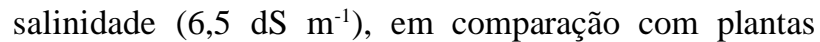
irrigadas com água de menor salinidade $\left(0,5 \mathrm{dS} \mathrm{m}^{-1}\right)$. Para plantas oriundas de sementes que não foram tratadas com o regulador vegetal verificou-se redução de $130,76 \mathrm{~cm}^{2}$ planta $^{-1}$ por aumento unitário na condutividade elétrica da água, com redução total de $43,1 \%$ nas plantas submetidas à maior salinidade (FIG. 1B). A redução da área foliar, com o aumento do nível salino da água de irrigação é provavelmente, um processo fisiológico de defesa das plantas, no qual elas procuram se proteger da perda de água, reduzindo sua superfície de transpiração (TESTER; DAVEMPORT, 2003).

A altura das plantas (FIG. 2A) foi reduzida em resposta à salinidade da água de irrigação, independente do tratamento das sementes com cloreto de mepiquat, sendo ajustada equação linear decrescente, de forma que as plantas mais altas foram obtidas na salinidade de $0,5 \mathrm{dS} \mathrm{m}^{-1}(50,0 \mathrm{~cm})$, enquanto as menores foram obtidas na salinidade de $6,5 \mathrm{dS} \mathrm{m}^{-1}(33,9 \mathrm{~cm})$. A partir da equação de regressão ajustada, verifica-se redução de cerca de $2,72 \mathrm{~cm}$ planta $^{-1}$ por aumento unitário na condutividade elétrica na água utilizada na irrigação, e redução total de $32,54 \%$ nas plantas irrigadas com água de salinidade $6,5 \mathrm{dS} \mathrm{m}^{-1}$ (FIG 2A). Efeito negativo da salinidade da água ou do solo sobre a altura de plantas do algodoeiro tem sido constatado por diversos autores como Jácome et al. (2003) e Siqueira et al. (2005).

Foi observado resposta significativa e negativa do aumento da salinidade da água de irrigação sobre massa seca do caule (MSC), e das folhas (MSF) e da parte vegetativa

Figura 1 - Número de folhas por planta (A) e área foliar (B) de algodoeiro em função do tratamento das sementes com cloreto de mepiquat e da irrigação com água salina
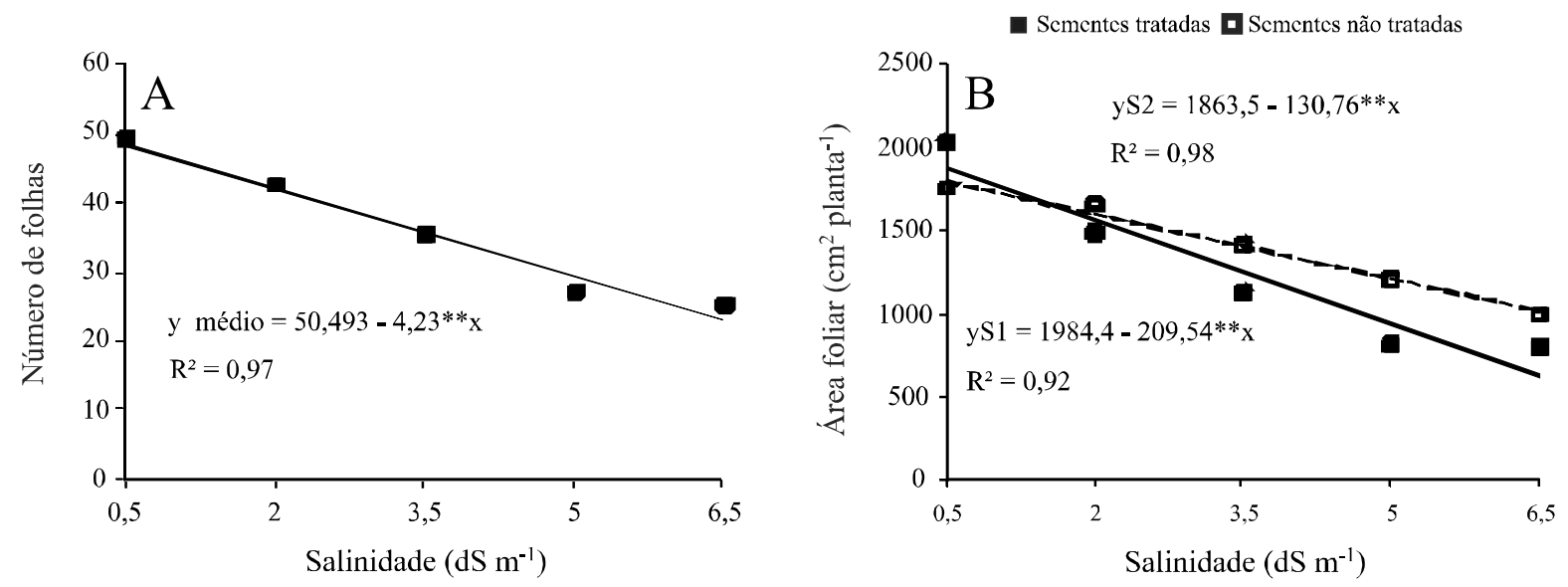

Figura 2 - Altura de plantas e acúmulo de massa seca (MSC, MSF e MSPV) do algodoeiro em função do tratamento das sementes com cloreto de mepiquat e da irrigação com água salina
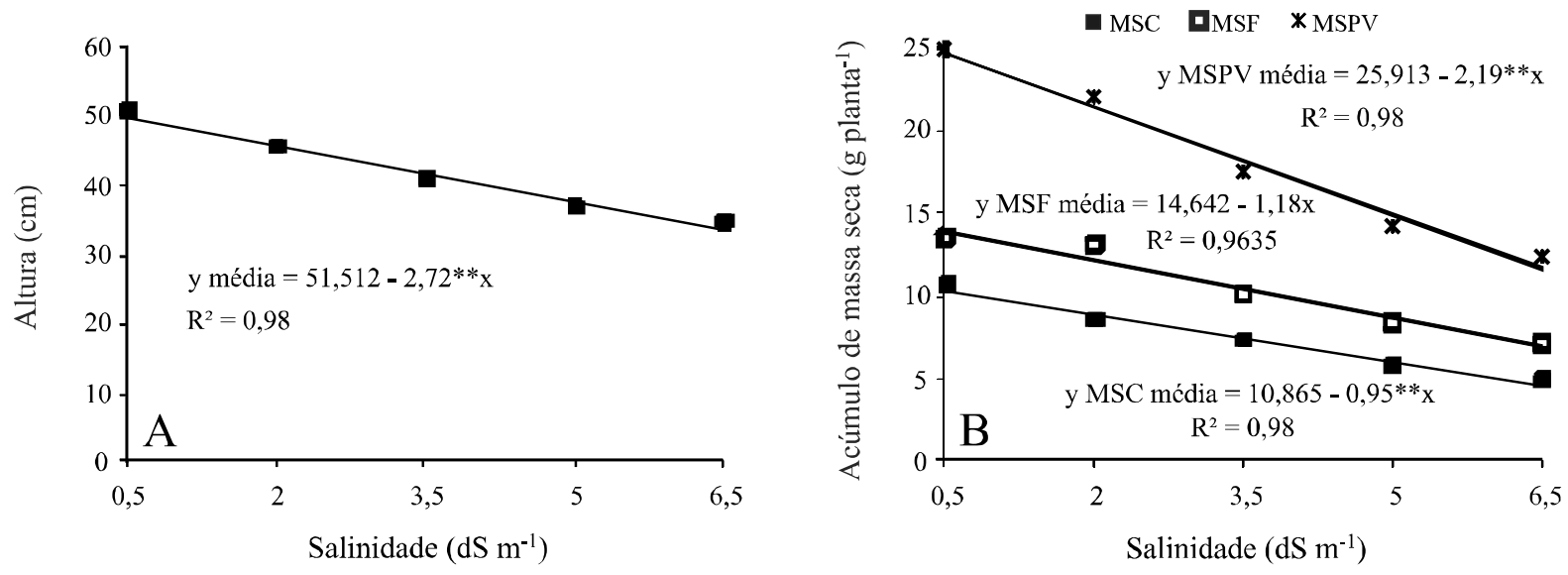
(MSPV), sendo observada perda em cerca de 0,95 e 1,18 e 2,65 g planta $^{-1}$, respectivamente, por aumento unitário da salinidade, com reduções totais de 54,8\% para MSC, 50,3\% para MSF e 52,9\% MSPV nas plantas irrigadas com água de condutividade elétrica de $6,5 \mathrm{dS} \mathrm{m} \mathrm{m}^{-1}$, em comparação com aquelas irrigadas com água de $0,5 \mathrm{dS} \mathrm{m}^{-1}$ (FIG. 2B). Estudos realizados com diferentes espécies de interesse agronômico têm demonstrado o efeito deletério da salinidade sobre a atividade fotossintética e desenvolvimento das plantas (CORREIA et al., 2009; JACOME et al., 2003). Para Ayers e Westcot (1999), o aumento da pressão osmótica do substrato atua de forma negativa sobre os processos fisiológicos, reduzindo a absorção de água pelas raízes, inibindo a atividade meristemática e o alongamento celular, advindo, como consequência, a redução no crescimento das culturas.

A cultura do algodoeiro, apesar de ser considerada tolerante à salinidade, pode sofrer reduções substanciais no crescimento e produção, quando submetida ao elevado estresse salino. Esta situação evidencia que as respostas à salinidade variam de acordo com o genótipo e o estádio de desenvolvimento da planta (FAGERIA; GHEYI, 1997).

Não houve efeito da salinidade sobre a partição de massa seca entre caule e folha do algodoeiro, sendo, no entanto, observada diferença quanto ao tratamento das sementes com o regulador vegetal. Para as plantas oriundas de sementes tratadas houve variação na percentagem de MSC de 37,1 a 40,0\% nas salinidades de 5,0 e 0,5 $\mathrm{dS} \mathrm{m}^{-1}$, respectivamente, com participação percentual média de $38,8 \%$, e, consequentemente, $61,7 \%$ para MSF (FIG. 3A). Com relação às sementes não tratadas houve variação de 42,2\% (2,0 dS m $\left.{ }^{-1}\right)$ a 47,5\% (0,5 dS m $\left.{ }^{-1}\right)$, com distribuição média de 44,4\% para MSC e 55,6\% para MSF (FIG. 3B).
Essa maior participação da MSF nas plantas provenientes de sementes tratadas com cloreto de mepiquat, pode ser explicado pelo efeito fisiológico do regulador vegetal. De acordo com Reddy (1990) a aplicação do cloreto de mepiquat ocasiona folhas com maiores pesos específicos, embora com menor tamanho, mas mais espessas, de forma que a planta estaria acumulando parte de sua energia nas folhas em função de reduzidas taxas de crescimento de novas estruturas.

Verificou-se que a salinidade da água não afetou a AFE, sendo obtido valor médio de $127,1 \mathrm{~cm}^{2} \mathrm{~g}^{-1} \mathrm{MSF}$. Essa resposta demonstra que o efeito da salinidade foi proporcional na expansão do limbo foliar, bem como sobre a produção de fitomassa, visto que, a AFE expressa a espessura da folha. Em trabalhos desenvolvidos com a cultura do meloeiro, Porto Filho et al. (2006) verificaram que a salinidade provocou redução na AFE, devido ao efeito ser mais severo na área foliar que na massa seca da folha. No entanto, vale salientar que o meloeiro é considerado uma cultura menos tolerante à salinidade do que o algodoeiro.

Para a RAF também não houve efeito da salinidade, sendo, no entanto, foi verificada interação significativa entre salinidade da água de irrigação e o tratamento das sementes com cloreto de mepiquat, de forma que foi observada resposta variada em função do uso ou não do regulador vegetal. Para as plantas oriundas de sementes tratadas houve redução da RAF em resposta ao aumento da salinidade, no entanto, após o segundo nível salino aplicado (2,0 dS m $\left.{ }^{-1}\right)$, houve redução do efeito da salinidade e foi observado que a RAF manteve-se praticamente constante, apresentando valor médio de $71,8 \mathrm{~cm}^{2} \mathrm{~g}^{-1} \mathrm{MSPV}$, entre os quatro maiores níveis salinos. Comparando-se a RAF obtida na menor salinidade $\left(85,7 \mathrm{~cm}^{2} \mathrm{~g}^{-1} \mathrm{MSPV}\right)$ com a média das demais salinidades, houve redução de 16,2\% (FIG. 4).

Figura 3 - Partição de massa seca entre caule e folhas do algodoeiro em função da salinidade da água de irrigação em plantas provenientes de sementes tratadas (A) e não tratadas com cloreto de mepiquat (B)

A

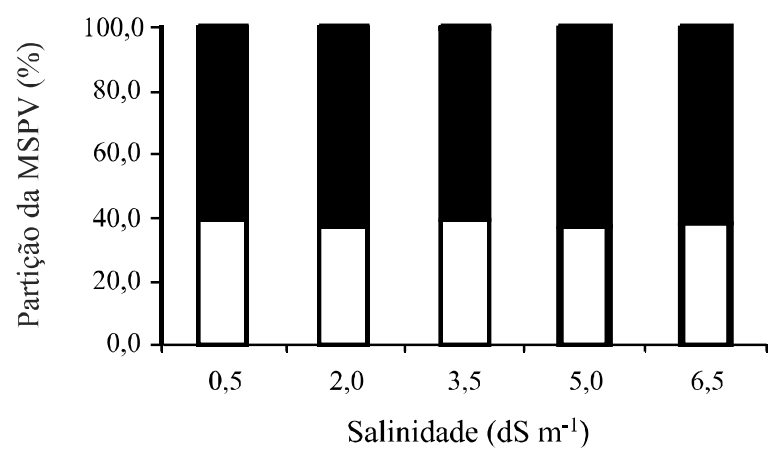

$\mathrm{B}$

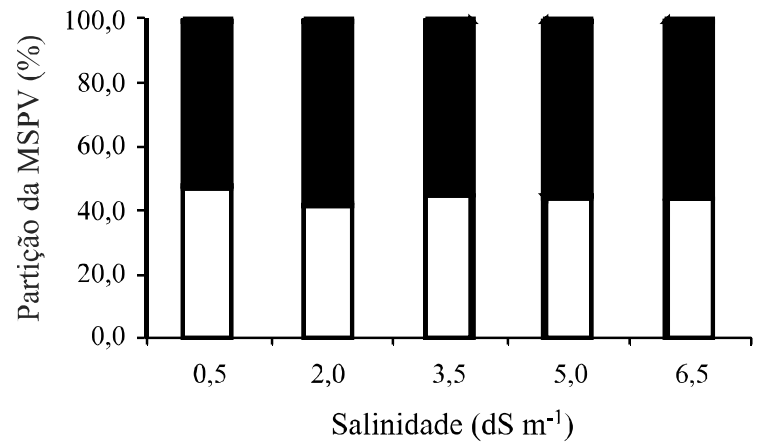

- MSC MSF 
Figura 4 - Razão de área foliar (B) do algodoeiro em função do tratamento das sementes com cloreto de mepiquat e da irrigação com água salina

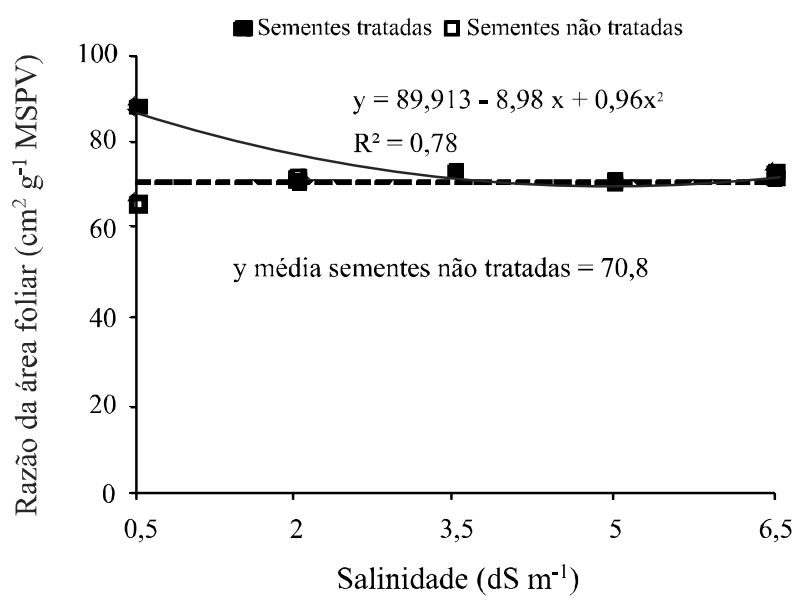

Trabalhando com a cultura da mamoneira, Cavalcanti et al. (2005) também não observaram efeito da salinidade sobre a RAF, enquanto Porto Filho et al. (2006) verificaram redução na RAF em meloeiro em função do aumento da salinidade. Essas divergências entre os resultados podem ser atribuídas às diferentes espécies estudadas, bem como às condições de cultivo utilizadas, evidenciando assim, a importância da avaliação deste índice fisiológico de crescimento das plantas, pois a RAF representa a dimensão relativa do aparelho fotossintético, sendo bastante apropriado para avaliar os efeitos genotípicos e ambientais sobre os vegetais.

\section{Efeito do regulador vegetal}

O número de folhas não foi influenciado pelo tratamento das sementes com regulador vegetal, sendo verificado um valor médio de 33,7 folhas por planta, no entanto, as plantas oriundas de sementes tratadas com cloreto de mepiquat apresentaram cerca de $14,3 \%$ de folhas a mais que as plantas provenientes de sementes não tratadas (TAB. 3). Na literatura são encontrados diversos trabalhos que demonstram o efeito do cloreto de mepiquat sobre o desenvolvimento do algodoeiro, no entanto, não há relatos do efeito desse regulador vegetal sobre a emissão de folhas.

Avaliando o efeito do regulador vegetal isoladamente sobre a área foliar, verificou-se que o tratamento das sementes com cloreto de mepiquat promoveu menor crescimento de folhas, resultando numa menor área foliar (1.251,0 $\mathrm{cm}^{2}$ planta $\left.^{-1}\right)$ em comparação com as sementes não tratadas $\left(1.405,8 \mathrm{~cm}^{2}\right.$ planta $\left.^{-1}\right)$, resultando assim, em diferença percentual de $11,0 \%$ (TAB. 3). Esses resultados evidenciam que o efeito do cloreto de mepiquat é mais notável no tamanho das folhas do que na emissão foliar. Trabalhando com concentrações e tempos de embebição de sementes de algodão, cultivar IPR-120, em cloreto de mepiquat e ao utilizarem a concentração de 7,5\% e embebição por 12 horas, condições semelhantes às utilizadas no presente trabalho, Nagashima et al. (2005) verificaram redução significativa na área foliar por planta, bem como na área foliar por folha, obtendo-se diferenças percentuais em cerca de 23,6 e 29,3\%, respectivamente, valores esses maiores que a diferença percentual obtida neste trabalho. Outros autores também constataram redução na área foliar do algodoeiro em resposta à aplicação de cloreto de mepiquat via foliar (CORDÃO SOBRINHO et al., 2007) ou via tratamento de sementes (NAGASHIMA et al., 2010).

O tratamento das sementes com o regulador vegetal acarretou plantas com menor altura $(34,7 \mathrm{~cm})$, resultando em redução de $29,6 \%$ na altura das plantas em comparação com plantas oriundas de sementes não tratadas $(49,3 \mathrm{~cm})$, conforme mostrado na Tabela 3. Teixeira et al. (2008) estudando o efeito do regulador vegetal no algodoeiro, cv. FMX 986, verificaram redução de aproximadamente $38 \%$, valor esse próximo ao obtido neste trabalho, enquanto Nagashima et al. (2007) observaram 50,3\%. A redução na altura das plantas em resposta ao cloreto de mepiquat pode ser atribuída ao fator antigiberelina do produto (LAMAS, 2001), ou seja, inibidor da síntese de giberelina.

Em conseqüência do efeito do cloreto de mepiquat sobre o desenvolvimento foliar e sobre a altura das plantas, houve diferença significativa no acúmulo de massa seca nas plantas, de forma que os menores valores foram observados

Tabela 3 - Número de folhas (NF), área foliar (AF), altura de plantas (ALT), massa seca de folhas (MSF), de caule (MSC) e da parte vegetativa (MSPA) do algodoeiro em função do tratamento de sementes com cloreto de mepiquat

\begin{tabular}{lllllclll}
\hline \multicolumn{1}{c}{ Sementes } & NF & AF & ALT & MSC & MSF & MSPV & AFE & RAF \\
\hline Tratadas & $31,1 \mathrm{a}^{*}$ & $1251,0 \mathrm{~b}$ & $34,7 \mathrm{~b}$ & $6,2 \mathrm{~b}$ & $9,9 \mathrm{~b}$ & $16,1 \mathrm{~b}$ & $124,1 \mathrm{a}$ & $70,8 \mathrm{a}$ \\
Não Tratadas & $36,3 \mathrm{a}$ & $1405,8 \mathrm{a}$ & $49,3 \mathrm{a}$ & $8,9 \mathrm{a}$ & $11,0 \mathrm{a}$ & $19,9 \mathrm{a}$ & $130,1 \mathrm{a}$ & $74,6 \mathrm{a}$ \\
Média & 33,7 & 1328,4 & 42,0 & 7,66 & 10,5 & 18,16 & 127,1 & 72,7 \\
\hline
\end{tabular}

*Médias seguidas pela mesma letra nas colunas não diferem entre si pelo teste Tukey ao nível de 5\% 
nas plantas oriundas de sementes tratadas com regulador vegetal, sendo verificadas diferenças percentuais de 30,3\% para MSC, $10 \%$ para MSF e de $17,5 \%$ para MSPV, em comparação às plantas oriundas de sementes não tratadas (TAB. 3). Esses resultados estão de acordo com os obtidos por Nagashima et al. (2007) que constataram reduções nos parâmetros vegetativos de plantas provenientes de sementes tratadas com o regulador vegetal.

Apesar de ter havido efeito do tratamento das sementes com o regulador vegetal sobre o desenvolvimento foliar e sobre o acúmulo de massa seca, não foi observado resposta significativa para a área foliar específica (AFE) nem para a razão de área foliar (RAF), apresentando valores médios de 127,1 $\mathrm{cm}^{2} \mathrm{~g}^{-1}$ MSF para AFE e de $72,7 \mathrm{~cm}^{2} \mathrm{~g}^{-1}$ MSPV para RAF. Considerando os valores obtidos em termos absolutos verifica-se que o tratamento das sementes proporcionou plantas com menores valores, com diferenças percentuais de 4,6 e 5,1\% para AFE e RAF, respectivamente (TAB. 3). Souza et al. (2007) verificaram que a aplicação de cloreto de mepiquat promoveu a formação de folhas mais espessas e menores. Segundo esses autores, plantas em tais condições tendem a ter folhas menores, pois esse regulador atua inibindo o alongamento celular fazendo com que as folhas sejam reduzidas, no entanto, ainda segundo esses autores, existe um efeito compensatório que é refletido no aumento da espessura foliar.

\section{CONCLUSÕES}

1. Todas as características avaliadas foram reduzidas com o aumento da salinidade da água de irrigação, com maiores reduções para área foliar (média de 65,8\%) e massa seca da parte vegetativa $(64 \%)$;

2. O tratamento das sementes com cloreto de mepiquat afetou o desenvolvimento das plantas, independente da salinidade;

3. O tratamento das sementes com cloreto de mepiquat não alterou a resposta do algodoeiro à salinidade.

\section{REFERÊNCIAS}

AYERS, R. S.; WESTCOT, D. W. A qualidade da água na agricultura. Campina Grande: UFPB, 1999, 218 p. (Estudos FAO Irrigação e Drenagem, 29 revisado).

BALDO, R. et al. Comportamento do algodoeiro cultivar delta opal sob estresse hídrico com e sem aplicação de bioestimulante. Ciência e Agrotecnologia, v. 33, p. 18041812, 2009. Número especial.
BOGIANI, J. C.; ROSOLEM, C. A. Sensibilidade de cultivares de algodoeiro ao cloreto de mepiquat. Pesquisa Agropecuária Brasileira, v. 44, n. 10, p. 1246-1253, 2009.

CARLESSO, R. et al. Efeito da lâmina de irrigação na senescência foliar do feijoeiro. Irriga, v. 12, n. 04, p. 545-556, 2007.

CAVALCANTI, M. L. F. et al. Índices ecofisiológicos da mamoneira sob estresse salino. Revista Brasileira deEngenharia Agrícola e Ambiental, v. 09, p.66-70, 2005 Suplemento.

CORDÃO SOBRINHO, F. P. et al. Crescimento e rendimento do algodoeiro BRS-200 com aplicações de cloreto de mepiquat e lâminas de irrigação. Revista Brasileira de Engenharia Agrícola e Ambiental, v. 11, n. 03, p.284-292, 2007.

CORREIA, K. G. et al. Crescimento, produção e características de fluorescência da clorofila a em amendoim sob condições de salinidade. Revista Ciência Agronômica, v. 40, n. 04, p. 514-521, 2009.

COSTA, A. C. P., MACEDO, F. S., HONCZAR, G. Algodão. In: AGRONEGÓCIO brasileiro. São Paulo: Sonopress Gráfica, 2008. p. 24-29.

EMPRESA BRASILEIRA DE PESQUISA AGROPECUÁRIA (EMBRAPA). Manual de métodos de análise de solo. 2. ed. Rio de Janeiro: Centro Nacional de Pesquisa de Solos, 1997. 212 p.

FAGERIA, N. K.; GHEYI, H. R. Melhoramento genético das culturas e seleção de cultivares. In: GHEYI, H. R.; QUEIROZ, J. E.; MEDEIROS, J. F. (Ed.). Manejo e controle da salinidade na agricultura irrigada. Campina Grande: UFPB, 1997. p. 365-385.

FERREIRA, P. A. et al. Produção relativa do milho e teores folheares de nitrogênio, fósforo, enxofre e cloro em função da salinidade do solo. Revista Ciência Agronômica, v. 38, n. 01, p. 7-16, 2007.

FURTADO, R. F. et al. Efeito da salinidade na germinação de sementes de algodão. Revista Ciência Agronômica, v. 38, n. 02, p. 224-227, 2007.

JACOME, A. G. et al. Comportamento produtivo de genótipos de algodão sob condições salinas. Acta Scientiarium Agronomy, v. 25 , n. 01, p. 187-194, 2003.

LAMAS, F. M. Estudo comparativo entre cloreto de mepiquat e cloreto de chlormequat aplicados no algodoeiro. Pesquisa Agropecuária Brasileira, v. 36, n. 02, p. 265-272, 2001.

MUNNS, R. Comparative physiology of salt and water stress. Plant, Cell and Environment, v. 25, n. 02, p. 239-250, 2002.

MUNNS, R. Genes and salt tolerance: bringing them together. New Phytologist, v. 167, n. 03, p. 645-663, 2005.

NAGASHIMA, G. T. et al. Desenvolvimento de plantas de algodão provenientes de sementes embebidas com cloreto de mepiquat. Pesquisa Agropecuária Brasileira, v. 40, n. 09, p. 943-946, 2005.

NAGASHIMA, G. T. et al. Desenvolvimento do algodoeiro em resposta a modo de aplicação e doses de cloreto de mepiquat via sementes. Ciência Rural, v. 40, n. 01, p.7-11, 2010.

NAGASHIMA, G. T. et al. Embebição de sementes e aplicação foliar com cloreto de mepiquat no crescimento e produção do algodoeiro. Ciência e Agrotecnologia, v. 31, n. 04, p. 1027-1034, 2007. 
PORTO FILHO, F. Q. et al. Crescimento do meloeiro irrigado com águas de diferentes salinidades. Horticultura Brasileira, v. 24, n. 03, p.334-341, 2006.

REDDY, V. R., BAKER, D. N., HODGES, H. F. Temperature and mepiquat chloride on cotton canopy architecture. Agronomy Journal, v. 82, p. 190-195, 1990.

SILVA, B. B.; RAO, T. V. R. The CWSI variations of a cotton crop in a semi-arid region of Northeast Brazil. Journal of Arid Environments, v. 62, n. 04, p. 649-659, 2005.

SIQUEIRA, E. C. et al. Crescimento do algodoeiro colorido sob diferentes níveis de salinidade da água de irrigação.
Revista Brasileira de Engenharia Agrícola e Ambiental, v. 09, p. 263-267, 2005. Suplemento.

SOUZA, F. S. et al. Efeito do Cloreto de Mepiquat na Espessura de Folhas do Algodoeiro em Função da Temperatura. Revista Brasileira de Biociências, v. 05, n. 02, p. 315-317, 2007.

TAIZ, L.; ZEIGER, E. Plant physiology. 3. ed. Porto Alegre: Artmed, 2009. 719 p.

TEIXEIRA, I. R.; KIKUTI, H.; BORÉM, A. Crescimento e produtividade de algodoeiro submetido a cloreto de mepiquat $\mathrm{e}$ doses de nitrogênio. Bragantia, v. 67, n. 04, p. 891-897, 2008.

TESTER, M.; DAVENPORT, R. $\mathrm{Na}^{+}$tolerance and $\mathrm{Na}^{+}$transport in higher plants. Annals of Botany, v. 91, p. 503-527, 2003. 